\title{
Polymorphism of white muscle myosin and parvalbumins in the genus Barbus (Teleostei: Cyprinidae)
}

\author{
F. Huriaux*, P. Vandewalle† ANd B. Focant* \\ * Laboratoire de Biologie cellulaire et tissulaire, Université de Liège, rue de Pitteurs, 20, \\ $B$-4020 Liège and $\uparrow$ Laboratoire de Morphologie fonctionnelle, Université de Liège, \\ quai Van Beneden, 22, B-4020 Liège, Belgium
}

(Received 25 January 1992, Accepted 11 April 1992)

\begin{abstract}
Muscle proteins were investigated in two large European barbels, Barhus barbus and $B$. meridionalis, and in four small tropical barbels native to SE Asia: $B$. conchonius, $B$. tetrazona, $B$. sachsi and $B$. tittera. Polyacrylamide gel electrophoresis was used to analyse myosin heavy and light chains and parvalbumin isotypes from white trunk muscle. Each species could be biochemically identified. The myosin subunit and parvalbumin isotype patterns obtained for the two European barbels were similar. The Asian barbels, on the other hand. not only differed from the European species but displayed a greater diversity within their group. These biochemical results are largely in agreement with morphological and genetic data, but fail to substantiate suggested close relationships between Asian barbel species.
\end{abstract}

Key words: myosin; light chains; heavy chains; parvalbumins; fish; Barbus.

\section{INTRODUCTION}

The genus Barbus (Cyprinidae) currently comprises some 800 species in Europe, Africa and Asia. These species present considerable diversity. The common species Barbus barbus (L.) is the main representative in Europe and has the largest distribution area, from the Atlantic to the Black Sea. It is taxonomically related to another European barbel, the Mediterranean barbel Barbus meridionalis R. (Almaça, 1984). These two river fishes have been found to hybridize naturally in southern France, producing fertile descendants (Berrebi et al., 1987). Berrebi et al. (1990) have shown, by genetic differentiation, that African barbels form two distinct lineages: large, tetraploid species and small, diploid ones. For these authors, the large African barbels resemble, in many respects, their European counterparts, which are also tetraploid. The small African and Asian specimens, on the other hand, would appear to constitute another, less homogeneous group. The heterogeneity of the Asian barbels is further illustrated by the fact that they are often subdivided into three genera (Puntius, Capoeta and Barbodes) according to the number of barbs (Berrebi et al., 1990).

Myosin from fish muscles exhibits a subunit structure and isozymic distribution resembling those of mammalian muscle myosin. Fish white-fibre myosin is composed of two heavy chains (HC, $200 \mathrm{kD})$ and three types of light chains $\left(\mathrm{LC}_{1}, \mathrm{LC}_{2}\right.$ and $\mathrm{LC}_{3}, 16$ to $25 \mathrm{kD}$ ). Light chains in various teleosts have been extensively studied by polyacrylamide gel electrophoresis (Focant et al., 1976; Huriaux \& Focant, 1977, 1985; Watabe et al., 1982; Huriaux et al., 1983, 1990; Focant \& Pequeux, 1985; Rowlerson et al., 1985; Ochiai et al., 1988, 1990; Martinez et al., $1990 a, b) . \mathrm{LC}_{1}$ and $\mathrm{LC}_{3}$, especially the latter, show significant species-related 
characteristics. A single isoform of myosin heavy chain has generally been detected (Karasinsky \& Kilarsky, 1989; Martinez et al., 1990a, b). Fish sarcoplasm contains low-molecular-weight calcium-binding proteins, the parvalbumins. These are abundant in white fibres and frequently present several isotypes (for a review, see Gerday, 1982). Electrophoretic analysis of myosin light chains and parvalbumins has made it possible to discriminate between closely related species of Gobiidae (Focant \& Joyeux, 1988), Serranidae (Focant et al., 1988), Labridae (Focant et al., 1990) and Cichlidae (Focant \& Vandewalle, 1991). So far, however, it has not been possible, by this means, to establish any phylogenetic correlations within a genus.

We have recently identified the myosin subunits and parvalbumin isotypes of several trunk and head muscles from Barbus barbus (Huriaux et al., 1990, 1991a, $b$; Focant et al., 1992). The white muscle myosin light chains exhibit species-specific properties as well as ones common to fish. A single type of heavy chain was found in trunk muscle but two isotypes were detected in head muscles. Three parvalbumin isotypes were identified in the dorso-lateral muscle; their distribution varies with fish size and according to the antero-posterior myotomal location, but is influenced neither by the growth rate nor by life style.

To gain a more detailed view of biochemical polymorphism in the genus Barbus we have compared, on polyacrylamide gels, the electrophoretic mobility of myosin heavy and light chains and parvalbumin isotypes from the trunk white fibres of the common barbel Barbus barbus (Linné, 1758), with the corresponding proteins from the Mediterranean barbel Barbus meridionalis Risso, 1826 and four tropical barbels native to regions of SE Asia, rosy barbel Barbus conchonius (HamiltonBuchanan, 1822), tiger barbel Barbus tetrazona (Bleeker, 1855), gold barbel Barbus sachsi Ahl, 1923 and cherry barbel Barbus titteya (Deraniyagala, 1929). These Asian species were previously chosen by Frankel for studies on the tissue-specificity and ontogenetic expression of isozymes in the genus Barbus (Varma \& Frankel, 1980; Frankel, 1983, 1985; Frankel \& Wilson, 1984, 1985).

\section{MATERIALS AND METHODS}

\section{MUSCLE SAMPLES}

B. meridionalis [seven specimens; standard length (S.L.) $12-14.5 \mathrm{~cm}$ ] were caught in the River Lergue (area of Montpellier, France). The Asian barbels were obtained from a local retail distributor in Liège. Three sets of experiments were performed; one $B$. conchonius (S.L. $4 \mathrm{~cm})$, two B. tetrazona $($ S.L. $3 \mathrm{~cm})$, three $B$. sachsi $($ S.L. $3 \mathrm{~cm})$ and three $B$. titteya $($ S.L. $2.4 \mathrm{~cm})$ were examined in each set. The whole dorso-lateral white muscle was dissected from the Asian barbels. In the case of $B$. meridionalis, only the anterior part of this white muscle located in front of the dorsal fin was used. The corresponding muscle samples from $B$. barbus have previously been analysed (Huriaux et al., 1990, 199la,b) and were used as references in this work.

The various muscles were minced and kept in 10 vol. of a solution containing $0.01 \mathrm{M}$ Tris$\mathrm{HCl}, 0.05 \mathrm{M} \mathrm{KCl}, 0.01 \mathrm{~m} \mathrm{DTT}, 50 \%$ glycerol $(\mathrm{v} / \mathrm{v}), 0.005 \% \mathrm{NaN}_{3}(\mathrm{w} / \mathrm{v}), \mathrm{pH} 7.5$, at $-20^{\circ} \mathrm{C}$ for one to several weeks.

\section{PREPARATION OF PROTEINS}

Actomyosin preparation, isolation of parvalbumin-containing sarcoplasmic extract, and incubation of samples were performed according to Huriaux et al. (1990).

\section{POLYACRYLAMIDE GEL ELECTROPHORESIS}

Vertical-slab polyacrylamide gel $(18 \times 8 \times 0.2 \mathrm{~cm})$ electrophoresis (PAGE) was used under several sets of conditions. 
Myosin light chains were separated in an $8 \mathrm{M}$ urea, $10 \%$ acrylamide gel at $\mathrm{pH} 8.6$ (Perrie \& Perry, 1970) or in a sodium dodecyl sulphate (SDS)-discontinuous-buffer system (separating gel: $20 \%$ acrylamide, $\mathrm{pH} 8.4$ ) according to Laemmli (1970) with the modifications described by Huriaux et al. (1990). Myosin heavy chains were discerned in a SDS-discontinuous-buffer system (separating gel: $6 \%$ acrylamide) according to Danieli-Betto et al. (1986), but with further inclusion of 30,40 or $50 \%$ glycerol (w/v) at $\mathrm{pH} 8.8$ or 8.4 (Huriaux et al., 1991 b). Parvalbumin isotypes were analysed in $10 \%$ glycerol $(\mathrm{w} / \mathrm{v}), 10 \%$ acrylamide gel at $\mathrm{pH} 8.6$ (Focant et al., 1981).

Conditions for staining with Coomassie Brilliant Blue R-250 and destaining have been previously described (Huriaux \& Focant, 1977). Densitometry was performed with a Helena Quick-Scan apparatus (Beaumont, Texas).

\section{RESULTS}

\section{MYOSIN LIGHT CHAINS}

Polyacrylamide gel electrophoresis in $8 \mathrm{M}$ urea at alkaline $\mathrm{pH}$ separates actomyosin subunits according to their size, shape and mainly their charge. Under our conditions, only tropomyosin and myosin light chains enter the gel [Fig. 1(a)]. The white-muscle myosin patterns displayed by $B$. barbus and $B$. meridionalis were similar, while the patterns obtained with the four Asian barbels presented some peculiarities: $\mathrm{LC}_{1}$ from $B$. conchonius migrated a little faster; for all four Asian fishes the mobility of $\mathrm{LC}_{3}$ was the same, but inferior to that of the corresponding light chain from both European specimens. All $\mathrm{LC}_{2}$ looked similar, sometimes yielding faster, minor bands which could reflect their level of phosphorylation or degradation.

In SDS-PAGE experiments, where proteins are separated according to their molecular weight, the various myofibrillar components can be observed [Fig. 1(b)]. In the alkaline discontinuous system, $B$. meridionalis can be distinguished from $B$. barbus by a slower troponin-I band. Moreover, $\mathrm{LC}_{3}$ appeared slightly faster and distinctly more heterogeneous in the seven specimens examined. These $\mathrm{LC}_{3}$ peculiarities did not arise from the presence of a co-migrating contaminant protein, as demonstrated by cutting the $\mathrm{LC}_{3}$ band from the urea gel and observing its migration on a SDS-gel, or by increasing the running $\mathrm{pH}$ to alter its electrophoretic mobility (Huriaux \& Focant, 1978). As for the white-muscle components from the Asian barbels, SDS-PAGE confirms the unique structure of $B$. conchonius myosin $\mathrm{LC}_{1}$, which exhibited a higher apparent molecular weight. As in the urea gels, all the $\mathrm{LC}_{2}$ chains appeared similar. However, each $\mathrm{LC}_{3}$ displayed a species-related migration rate at alkaline $\mathrm{pH}$. The electrophoretic mobility of $\mathrm{LC}_{3}$ from the various barbel species varies in the order: $B$. barbus $\leqslant B$. meridionalis $<B$. tetrazona $\leqslant$ $B$. sachsi $<B$. conchonius $<B$. titteya, corresponding to a molecular weight range of $17000-16300$.

\section{MYOSIN HEAVY CHAINS}

High-porosity SDS PAGE of white-muscle myosin heavy chains revealed a single band for each barbel species (Fig. 2). Under all electrophoretic conditions investigated, the heavy chains from $B$. barbus and $B$. meridionalis were very similar, while heavy-chain mobility was a little higher for the Asian fishes. These differences were confirmed by densitometric scanning of gels on which $B$. barbus myosin was allowed to comigrate with each Asian barbel myosin (Fig. 3). This procedure 


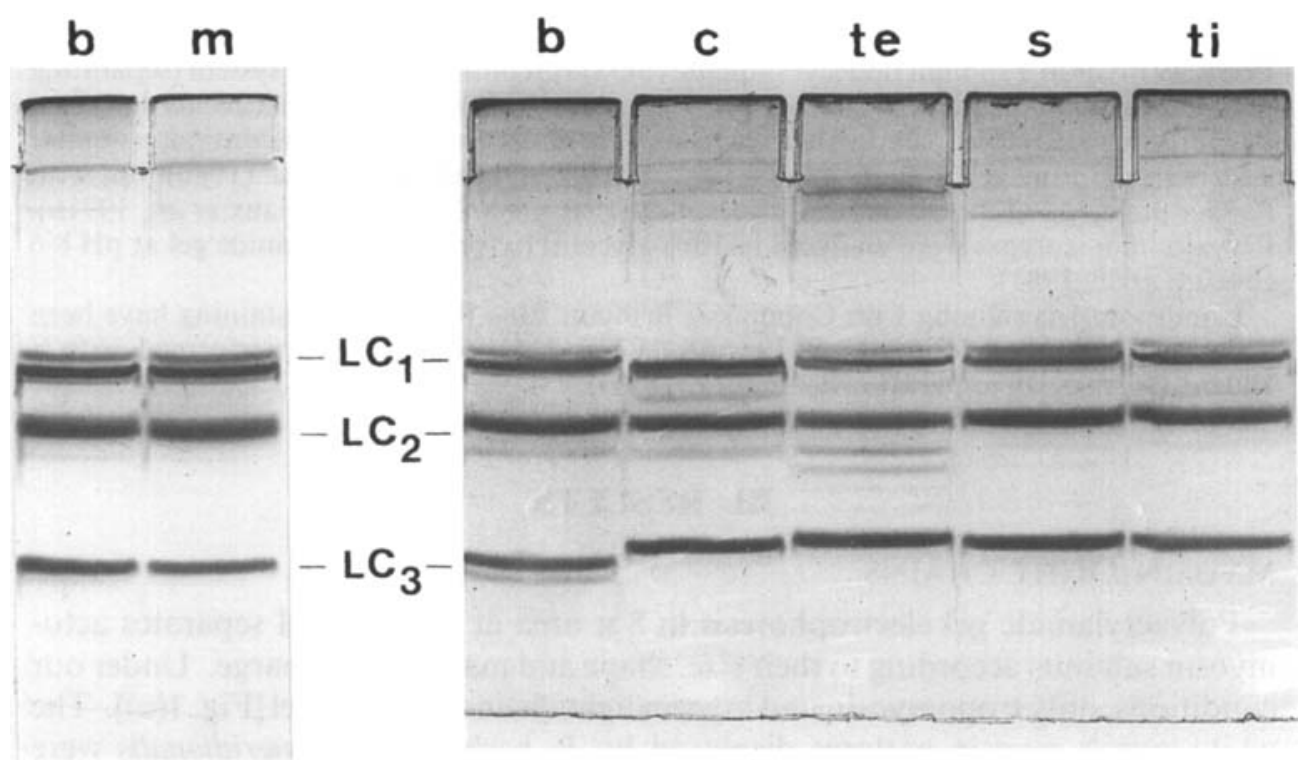

(a)

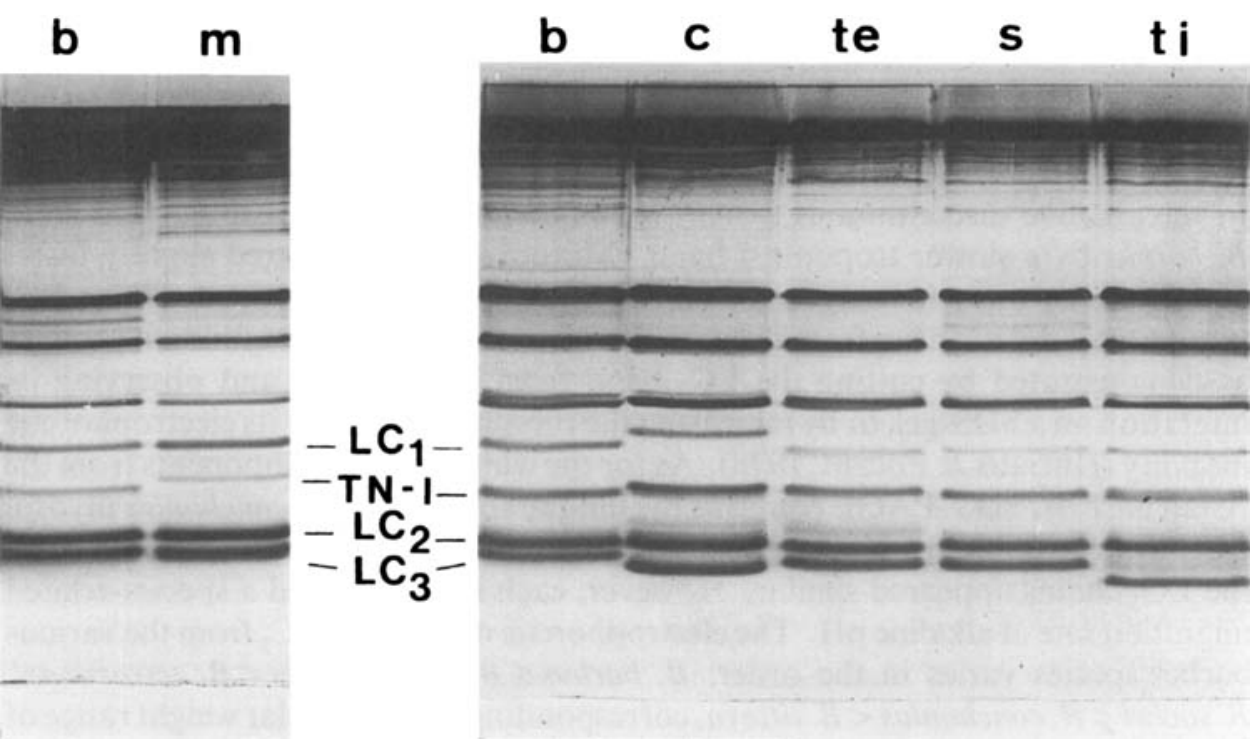

(b)

FIG. 1. (a) Urea and (b) SDS-PAGE of actomyosin from B. meridionalis (m), B. conchonius (c), B. tetrazona (te), B. sachsi (s) and B. titteya (ti) compared with B. barbus (b).

further allowed the detection of some very slight specific variations among the latter fishes. The relative mobility of the various heavy chains increased in the order: B. barbus $=B$. meridionalis $<B$. sachsi $<$ B. titteya $<B$. tetrazona $<B$. conchonius. 
b

m

b

C

te

S

ti

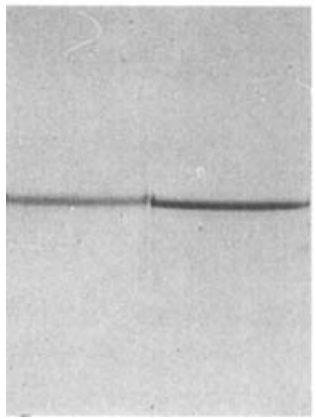

FIG. 2. SDS-PAGE at $\mathrm{pH} 8.8$ and $30 \%$ glycerol of myosin heavy chains from $B$. meridionalis $(\mathrm{m}), B$. conchonius (c), B. tetrazona (te), B. sachsi (s) and B. titteya (ti) compared with B. barhus (b).
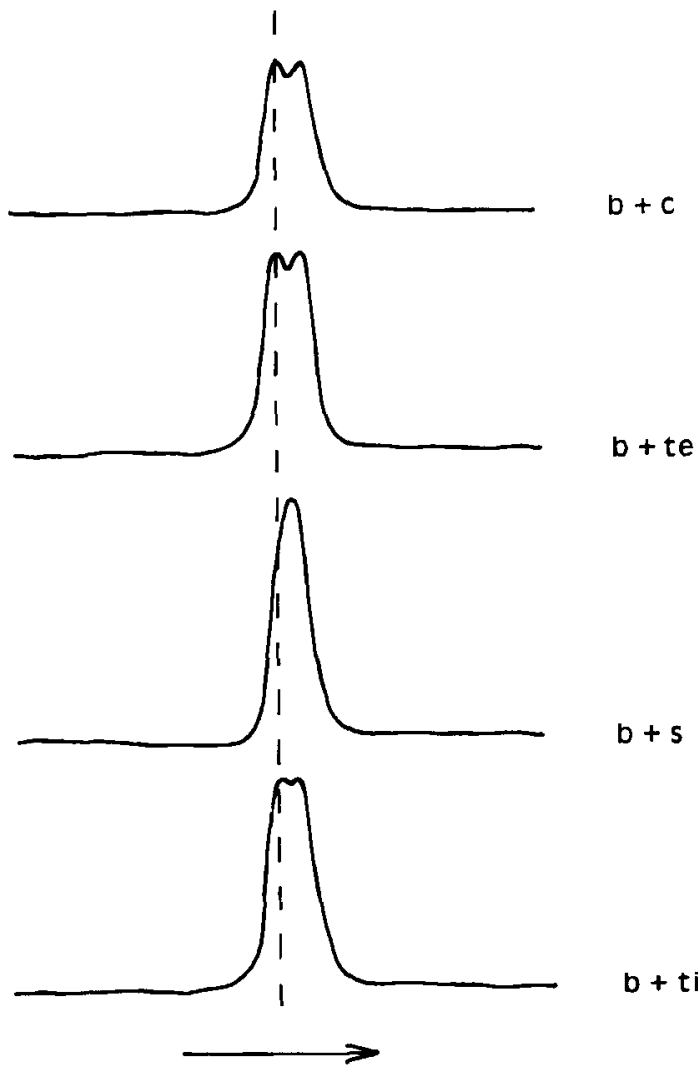

$b+t i$

Fig. 3. Densitometric traces of comigrating myosin heavy chains from B. barbus (b) with $B$. conchonius (c), B. terrazona (te), B. sachsi (s) or B. titteya (ti) in SDS-PAGE at pH 8.8 and $30 \%$ glycerol. The vertical dotted line indicates the $B$. barbus heavy-chain location. 


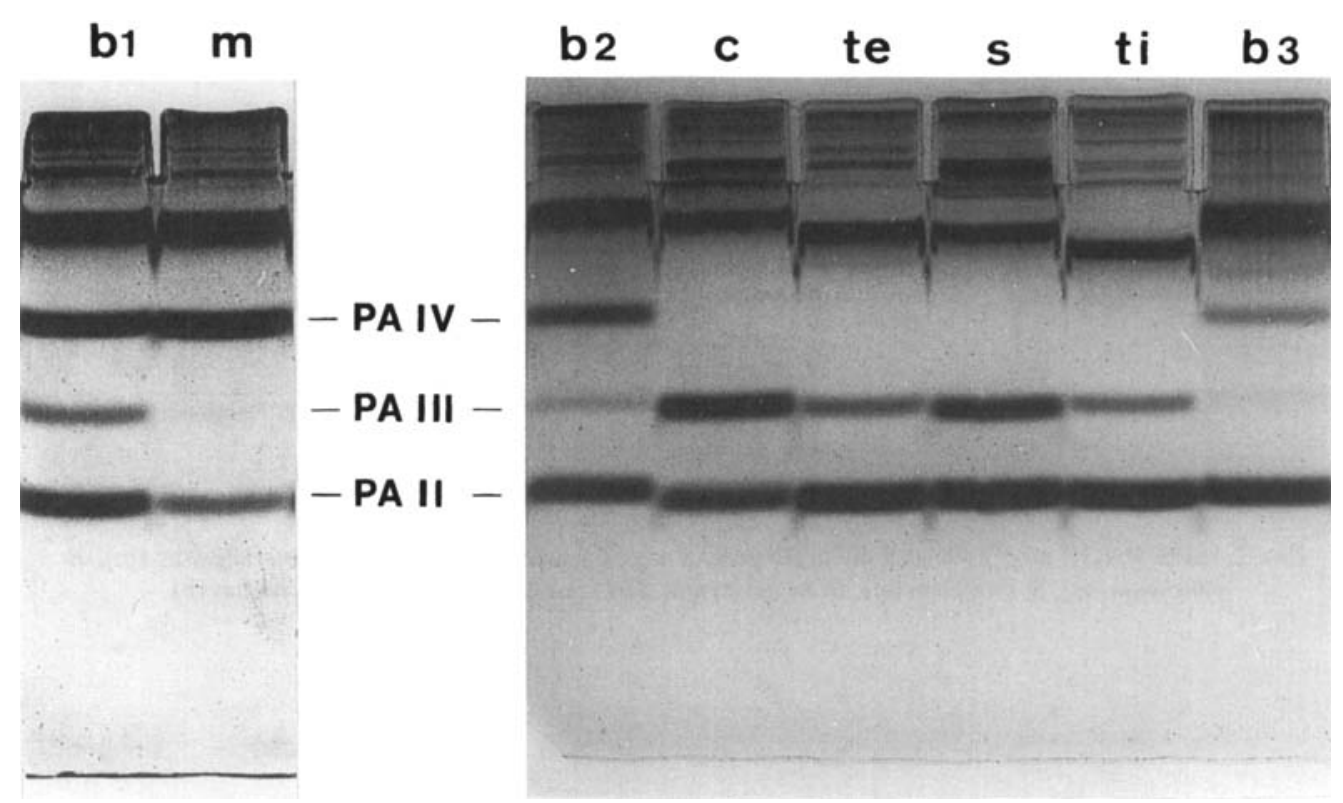

FIG. 4. Glycerol-PAGE of sarcoplasmic extracts from B. meridionalis $(\mathrm{m}), \boldsymbol{B}$. conchonius (c), B. tetrazona (te), B. sachsi (s) and B. titteya (ti) compared with B. barbus (b) of same size (b 1: $11.5 \mathrm{~cm} \mathrm{S.L.;} \mathrm{b} \mathrm{2:}$ $3.9 \mathrm{~cm} ; \mathrm{b} 3: 2 \cdot 4 \mathrm{~cm})$.

\section{PARVALBUMINS}

Sarcoplasm from $B$. barbus white trunk muscle contains three electrophoretic components displaying the mobility of carp parvalbumins II, III and IV (Huriaux et al., 1990). As the parvalbumin distribution varies according to fish size and the muscle-sample location, in the dorso-lateral muscle of $B$. barbus, any quantitative comparison requires suitable references. The anterior part of the $B$. meridionalis trunk muscle differed from the corresponding muscle portion from $B$. barbus specimens of the same size by the near absence of PA III and a lesser amount of PA II (Fig. 4 and Table I). In the case of the Asian barbels, the whole dorso-lateral muscle was used because of the small amount of tissue available. Only PA II and PA III isotypes appeared in the electrophoretic patterns of sarcoplasmic extracts from the four species, the stoichiometry of the two isotypes being species-specific except between B. tetrazona and B. titteya, where it appeared similar (Fig. 4 and Table I). This parvalbumin distribution is also very different from that observed in the B. barbus specimens of the same size: these exhibit little PA III but a noticeable amount of PA IV increasing with fish size.

\section{DISCUSSION}

Various morphological and genetic data demonstrate the considerable species variability of the genus Barbus (Almaça, 1984; Berrebi et al., 1990). This made it interesting to compare the electrophoretic properties of muscle proteins from various representatives of the genus. To this end, we chose to examine two large European barbels and four small Asian ones. 
TABle I. Percentage of parvalbumin isotypes in the dorso-lateral muscle from $B$. meridionalis $(\mathrm{m}), B$. conchonius $(\mathrm{c}), B$. tetrazona $(\mathrm{te}), B$. sachsi $(\mathrm{s})$ and $B$. titteya $(\mathrm{ti})$ compared with $B$. barbus (b) of same size

\begin{tabular}{|c|c|c|c|c|c|}
\hline Species & $\begin{array}{l}\text { Standard length } \\
(\mathrm{cm})\end{array}$ & PA I & PA II & PA III & PA IV \\
\hline $\begin{array}{l}\text { B. meridionalis* } \\
\text { B. barbus } \dagger\end{array}$ & $\begin{array}{c}12-14 \cdot 5 \\
11 \cdot 5\end{array}$ & - & $18+4$ & $1 \cdot 5 \pm 1$ & $\begin{array}{c}80 \cdot 5 \pm 4 \\
44\end{array}$ \\
\hline B. conchonius & 4 & - & $40 \pm 3$ & $60 \pm 3$ & - \\
\hline B. tetrazona ${ }_{+}^{+}$ & 3 & - & $84 \pm 3$ & $16 \pm 3$ & $\ldots$ \\
\hline B. sachsit+ & 3 & - & $60 \pm 4 \cdot 5$ & $40 \pm 4 \cdot 5$ & - \\
\hline B. titteyat & $2 \cdot 4$ & - & $83 \pm 4$ & $17 \pm 4$ & - \\
\hline B. barbusई & 4 & - & $\overline{59}$ & 7 & 34 \\
\hline B. barbus§ & 3 & - & 67 & 4 & 29 \\
\hline B. barbusई & $2 \cdot 4$ & - & 78 & 3 & 19 \\
\hline
\end{tabular}

*Anterior part of the dorso-lateral muscle; average of 21 scans.

+ Anterior part of the dorso-lateral muscle; from Huriaux et al. (1990).

$\ddagger$ Whole dorso-lateral muscle; average of 10 scans.

\$Wholc dorso-lateral muscle; from Huriaux et al. (1991a).

It is now well established that SDS-PAGE patterns of myosin light chains constitute a useful biochemical tool for characterizing fish species (Focant et al., 1976; Huriaux \& Focant, 1985; Rowlerson et al., 1985; Ochiai et al., 1988, 1990; Martinez et al., $1990 a, b$ ). These studies generally failed to reveal any phylogenetic correlations between electrophoretic patterns of the various marine or freshwater teleosts examined. Nevertheless, Ochiai et al. (1988, 1990), studying the physicochemical and immunochemical properties of light chains from several marine teleosts, reported structural similarities within some families.

The myosin light chains of the barbel species examined in this work exhibited the electrophoretic pattern typical of fish. Light and heavy chains from $B$. meridionalis behaved in the same way as the corresponding chains from $B$. barbus (Huriaux et al., 1990, 1991 b), apart from the minor migration difference exhibited by $\mathrm{LC}_{3}$ in SDS-PAGE. The present biochemical results are in agreement with morphological and genetic data which indicate that the two species are closely related. It is interesting to note that each European barbel showed a specific troponin-I in SDSPAGE; this regulatory protein might be used as an additional criterion for species differentiation. As for the Asian barbels, several differences were found in the myosin subunits, not only compared with the reference species $B$. barbus but also within the group itself. B. conchonius $\mathrm{LC}_{1}$ differed from all other electrophoretically similar $\mathrm{LC}_{1}$ chains. On urea gels, the Asian barbels all exhibited a same $\mathrm{LC}_{3}$ band, distinct from the European counterpart. On SDS gels, however, the myosin $\mathrm{LC}_{3}$ of each Asian fish exhibited a specific pattern, again different from that of the corresponding B. barbus chain. As previously reported (Huriaux \& Focant, 1985; Rowlerson et al., 1985; Ochiai et al., 1990), LC $_{3}$ is the light chain showing the greatest variability on SDS PAGE with an alkaline discontinuous buffer system. It thus appears to be the most characteristic of a species. In the present work, each barbel species could be identified according to the mobility of this light chain. This electrophoretic diversity may be due to a variable artefact affecting $\mathrm{LC}_{3}$ mobility at 
alkaline $\mathrm{pH}$ (Huriaux \& Focant, 1978), but, as in the case of $B$. conchonius $\mathbf{L C}_{1}$, it does seem to reflect structural differences between the $\mathrm{LC}_{3}$ chains of the various barbel species. It seems that any size or age effect on the $\mathrm{LC}_{3}$ mobility very likely can be ruled out; in the case of $B$. barbus, this myosin light chain has been shown to be electrophoretically identical from the embryo to the adult stage (Focant et al., 1992). Unlike $\mathrm{LC}_{3}, \mathrm{LC}_{2}$ was very similar in all species studied, suggesting it could be a protein that was highly conserved in the course of evolution (Focant et al., 1976; Huriaux \& Focant, 1985; Ochiai et al., 1988, 1990). On the other hand, the electrophoretic patterns of the myosin heavy chains from the four Asian barbels were also species-specific although unrelated to the light-chain patterns, and distinct from those of the European barbels.

Parvalbumins appear as another biochemical criterion for distinguishing related fish species, especially since they present several isotypes in Cyprinidae. Interspecific comparisons, however, must be made with caution: the qualitative and quantitative distribution of isotypes have been shown to vary, in the dorso-lateral muscle of $B$. barbus, with fish size, especially in the first developmental stages, and according to the myotomal location (Huriaux et al., 1990, 1991a; Focant et al., 1992). $B$. meridionalis parvalbumins were shown to resemble their $B$. barbus counterparts qualitatively but to differ quantitatively. The Asian barbels, on the other hand, clearly diverge from the European species in that only two parvalbumin isotypes were detected. The stoichiometry of these isotypes differed from one species to another, except for $B$. tetrazona and B. titteya. The absence of a PA IV isotype does not seem to be imputable to the small size of the specimens: in the case of $B$. barbus, PA IV was detected in the sarcoplasm of embryos $1 \mathrm{~cm}$ long (5 days postfertilization). On the other hand, the variable stoichiometry of PA II and PA III among Asian fishes was not related to their size.

The PAGE patterns of myosin subunits and parvalbumin isotypes from white trunk muscle can thus be used to differentiate six species of the genus Barbus, even the very near species $B$. barbus and $B$. meridionalis. On the whole, these biochemical results agree with the above-mentioned morphological, physiological, and genetic data: the two large European species appear closely related while the four small Asian species not only differ from the European fishes but also vary among themselves. On the basis of morphological features, $B$. conchonius and $B$. sachsi have sometimes been grouped in the genus Puntius while B. tetrazona and $B$. titteya were classified in the genus Capoeta. Frankel, however, pointed out that $B$. tetrazona and $B$. conchonius are closely related species, whereas a greater genetic distance exists between B. tetrazona and B. sachsi or B. titteya (Frankel, 1985; Frankel \& Wilson, 1985). Our biochemical results fail to confirm these close relationships. We find no correlation between the characteristics of myosin light chains, myosin heavy chains, and parvalbumins among any of the Asian species studied here, this excludes any phylogenetic comparison.

The authors wish to thank the Laboratoire d'Ichthyologie et de Parasitologie générale (Professor Quignard) of the Université des Sciences et des Techniques du Languedoc (Montpellier, France) and the Laboratoire de Démographie des Poissons et de Pisciculture (Dr J.-C. Philippart) of the Université de Liège (Belgium) for supplying some of the fishes used in this study. This work was supported by research grant 3.4516 .89 from the Belgian 'Fonds de la Recherche Scientifique Médicale'. P.V. and B.F. are Research Associates of the Fonds National de la Recherche Scientifique of Belgium. 


\section{References}

Almaça, C. (1984). Form relationships among western Palearctic species of Barbus (Cyprinidae, Pisces). Arquivos do Museu Bocage 2, 207-248.

Berrebi, P., Le Brun, N., Renaud, F.\& Lambert, A. (1987). Hybridation inter-spécifique de deux Cyprinidae (genre Barbus). Conséquence sur la spécificité parasitaire de D. gracile (Monogenea). In Actes du Colloque National du C.N.R.S. 'Biologie des Populations', I.A.S.B.S.E. (C. Bernard, ed.). Lyon.

Berrebi, P., Lévêque, C., Cattaneo-Berrebi, G., Agnèse, J. F., Guégan, J. F. \& Machordom, A. (1990). Diploid and tetraploid African Barbus (Osteichthyes, Cyprinidae): on the coding of differential gene expression. Aquatic Living Resources 3, 313-323.

Danieli Betto, D., Zerbato, E. \& Betto, R. (1986). Type 1, 2A, and 2B myosin heavy chain electrophoretic analysis of rat muscle fibers. Biochemical and Biophysical Research Communications 138, 981-987.

Focant, B. \& Joyeux, J. C. (1988). Essai de spéciation biochimique de six espèces de Gobiidés du littoral Languedocien. Commission Internationale pour l'Exploration Scientifique de la Mer Méditerranée. Rapports et Procès-Verbaux des Réunions 31, 257.

Focant, B. \& Pequeux, A. (1985). Comparative electrophoretic study of myosins and parvalbumins from three deep sea fishes: Mora moro R., Conocara murrayi K. and Coryphaenoides rupestris G. Bulletin de la Société Royale des Sciences de Liège 1, 55-64.

Focant, B. \& Vandewalle, P. (1991). Comparison of myosin subunits and sarcoplasmic parvalbumins of white and red trunk muscles from various species of African Cichlids. Application to an hybrid. Musée Royal de l'Afrique Centrale, Tervueren, Belgique. Annales, Sciences Zoologiques 262, 33-38.

Focant, B., Huriaux, F. \& Johnston, I. A. (1976). Subunit composition of fish myofibrils: the light chains of myosin. International Journal of Biochemistry 7, 129-133.

Focant, B., Jacob, M. F. \& Huriaux, F. (1981). Electrophoretic comparison of the proteins of some perch (Perca fluviatilis L.) head muscles. Journal of Muscle Research and Cell Motility 2, 295-305.

Focant, B., Viladiu, C. \& Vandewalle, P. (1988). Biochemical analysis of parvalbumins and myosin light chains from Mediterranean Serranids: first application to the systematic. Commission Internationale pour l'Exploration Scientifique de la Mer Méditerranée. Rapports et Procès-Verbaux des Réunions 31, 258.

Focant, B., Michel, C. \& Vandewalle, P. (1990). Use of the biochemical analysis of muscle proteins to help the classification of polychromic individuals of the genus Symphodus. Archives Internationales de Physiologie et de Biochimie 98, 87-93.

Focant, B., Huriaux, F., Vandewalle, P., Castelli, M. \& Goessens, G. (1992). Myosin, parvalbumin and myofibril expression in barbel (Barbus barbus L.) lateral white muscle during development. Fish Physiology and Biochemistry. In press.

Frankel, J. S. (1983). Lactate dehydrogenase tissue specificity and characterization in the teleost genus Barbus. Comparative Biochemistry and Physiology 76B, 103-105.

Frankel, J. S. (1985). Ontogenetic patterns of enzyme locus expression in Barbus hybrids (Cypriniformes, Teleostei). Comparative Biochemistry and Physiology 82B, 413-417.

Frankel, J.S. \& Wilson, R. V. (1984). Comparison of the spatial and temporal expression of supernatant malate dehydrogenase in Barbus hybrids (Cypriniformes, Teleostei). Comparative Biochemistry and Physiology 78B, 179-182.

Frankel, J. S. \& Wilson, R. V. (1985). Aberrant gene expression at the creatine kinase loci during Barbus hybrid development (Cypriniformes, Teleostei). Comparative Biochemistry and Physiology 80B, 463-466.

Gerday, C. (1982). Soluble calcium-binding proteins from fish and invertebrate muscle. Molecular Physiology 2, 63-87.

Huriaux, F. \& Focant, B. (1977). Isolation and characterization of the three light chains from carp white muscle myosin. Archives Internationales de Physiologie et de Biochimie 85, 917-929.

Huriaux, F. \& Focant, B. (1978). Effect of some factors on the molecular weight determination of a light chain $\left(\mathrm{LC}_{3}\right.$ ) of carp (Cyprinus carpio $\mathrm{L}$.) skeletal muscle myosin by 
SDS-polyacrylamide gel electrophoresis. Comparative Biochemistry and Physiology 61B, $195-198$.

Huriaux, F. \& Focant, B. (1985). Electrophoretic and immunological study of myosin light chains from freshwater teleost fishes. Comparative Biochemistry and Physiology $\mathbf{8 2 B}$, 737-743.

Huriaux, F., Lefèbvre, F. \& Focant, B. (1983). Myosin polymorphism in muscles of the toadfish, Opsanus tau. Journal of Muscle Research and Cell Motility 4, 223-232.

Huriaux, F., Vandewalle, P., Philippart, J. C. \& Focant, B. (1990). Electrophoretic comparison of myosin light chains and parvalbumins of trunk and head muscles from two barbel (Barbus barbus) populations. Comparative Biochemistry and Physiology 97B, 547-553.

Huriaux, F. Focant, B. \& Vandewalle, P. (1991a). Spatial and temporal distribution of the parvalbumin isotypes in barbel muscles. Journal of Muscle Research and Cell Motility 12, 114-115.

Huriaux, F., Vandewalle, P. \& Focant, B. (1991b). Myosin heavy chain isoforms in white, red and ventricle muscles of barbel (Barbus barbus L.). Comparative Biochemistry and Physiology 100B, 309-312.

Karasinski, J. \& Kilarski, W. (1989). Polymorphism of myosin isoenzymes and myosin heavy chains in histochemically typed skeletal muscles of the roach (Rutilus rutilus $\mathbf{L}$., Cyprinidae, fish). Comparative Biochemistry and Physiology 92B, 727-731.

Laemmli, U.K. (1970). Cleavage of structural proteins during the assembly of the head of bacteriophage T4. Nature (London) 227, 680-685.

Martinez, I., Ofstad, R. \& Olsen, R. L. (1990a). Electrophoretic study of myosin isoforms in white muscles of some teleost fishes. Comparative Biochemistry and Physiology 96B, 221-227.

Martinez, 1., Ofstad, R. \& Olsen, R. L. (1990b). Myosin isoforms in red and white muscles of some marine teleost fishes. Journal of Muscle Research and Cell Motility 11, $489-495$.

Ochiai, Y., Watabe, S. \& Hashimoto, K. (1988). Physicochemical and immunological properties of myosin light chains from the ordinary muscle of marine teleost fishes. Comparative Biochemistry and Physiology 90B, 347-353.

Ochiai, Y., Kobayashi, T., Watabe, S. \& Hashimoto, K. (1990). Mapping of fish myosin light chains by two-dimensional gel electrophoresis. Comparative Biochemistry and Physiology 95B, 341-345.

Perrie, W. T. \& Perry, S. V. (1970). An electrophoretic study of the low-molecular-weight components of myosin. Biochemical Journal 119, 31-38.

Rowlerson, A., Scapolo, P. A., Mascarello, F., Carpene, E. \& Veggetti, A. (1985). Comparative study of myosins present in the lateral muscle of some fish: species variations in myosin isoforms and their distribution in red, pink and white muscle. Journal of Muscle Research and Cell Motility 6, 601-640.

Varma, A. K. \& Frankel, J. S. (1980). A comparison of tissue esterases in the genus Barbus by vertical gel electrophoresis. Comparative Biochemistry and Physiology 65B, $267-273$

Watabe, S., Ochiai, Y. \& Hashimoto, K. (1982). Identification of 5,5'-dithio-bis-2nitrobenzoic acid (DTNB) and alkali light chains of piscine myosin. Bulletin of the Japanese Society of Scientific Fisheries 48, 827-832. 